\title{
Building Smart Cities by Using Enterprise GIS in Saudi Arabia
}

\author{
Ahmad M. Almontshery, Faisal M. Jamalallail \\ Department of Geography and Geographic Information Systems, Faculty of Arts, King Abdulaziz University, Jeddah, KSA \\ Email: aalmontshri@gmail.com, faisaljl@gmail.com, unikaugis@hotmail.com
}

How to cite this paper: Almontshery, A.M. and Jamalallail, F.M. (2019) Building Smart Cities by Using Enterprise GIS in Saudi Arabia. Journal of Geographic Information System, 11, 663-669. https://doi.org/10.4236/jgis.2019.116040

Received: September 29, 2019

Accepted: November 17, 2019

Published: November 20, 2019

Copyright $\odot 2019$ by author(s) and Scientific Research Publishing Inc. This work is licensed under the Creative Commons Attribution International License (CC BY 4.0).

http://creativecommons.org/licenses/by/4.0/

(c) (i) Open Access

\begin{abstract}
Big Cities and capitals are becoming overcrowded and hard to get future development prospect. New self-sustaining cities are becoming a smart substitutional solution to those old cities. Information and Communication Technology (ICT) and information technology infrastructure (ITI) are at the core of these new self-sustaining cities enabling highly integrated services and real-time city monitoring by a network of sensors, wireless devices, cameras, and unified portals connected to massive data centers. All that for creating sustainable economic development and high quality of life by empowering various keys like energy, economy, efficiency, environment, mobility, communication, governance, transportation, people and leverage the quality of life. The Geographic information system (GIS) playing a big role in the smart city architecture and Royal commission in industrial yanbu city (RCY) build their smart city based on Enterprise GIS and open access network (OAN). "Geospatial technologies, such as modern geographic information systems (GIS) and data capturing technologies, are at the heart of the smart city, because understanding the 'WHERE' component is critical for making an informed decision. Geospatial technologies largely meet these communication needs, while emphasizing the geographical aspect, which plays a fundamental role in optimizing the understanding and management of the urban space". [1].
\end{abstract}

\section{Keywords}

Information and Communication Technology (ICT), Information Technology Infrastructure (ITI), Geographic Information System (GIS), Smart City, Open Access Network (OAN), Royal Commission Yanbu (RCY)

\section{Introduction}

Transferring cities to become smart cities is massive national project which will 
change the city infrastructure, economy and demography, "The promise of smart cities-just like the process of building one-is difficult to define, as there are so many working parts and components to consider. These include smart buildings, smart governance, smart healthcare, smart transportation, smart security, smart energy, smart commerce and smart infrastructure" [2]. Using Geographic information system can be the key for quick and efficient smart city projects implementation. And here we explain in this article how the enterprise GIS can be a useful tool to consider when planning to transfer cities to become a smart.

Saudi Arabia announced its new transformation program called "Vision 2030" in April 2016. This ambitious yet achievable blueprint has clarified the goals of developing cities, achieving environmental sustainability, improving digital infrastructures, and expanding the variety of digital services.

This new initiative to transfer the Saudi cities to smart cities can make cities more effective and efficient, expanding industrial clusters and attracting more high value-added investments-as feasible ways to build up national competitiveness. In line with Saudi Arabia's vision, the Smart Yanbu Industrial City project has started to build upon the Saudi Arabian vision for transformation. Yanbu Industrial City needs to substantially increase the efficiency in which they operate and use their resources. Major efficiency improvements can be achieved by horizontally interconnecting individual systems such as electricity, water, security, waste management, transportation, but also security, environmental monitoring or weather intelligence. "Based on digital cities, intelligent cities distinguish themselves by seamless SOA integration with other fields and pervasive processes in decision-making, which can be accelerated by geospatial resources and technologies. As indicated in Section 1.1, wide availability of high-resolution geospatial data is important to advancement of GIS and crucial to intelligent cities". [3].

\section{Study Area}

We will take Yanbu Al-Saniyah (industrial yanbu )-kingdom of Saudi Arabia as a study area.

Yanbu Al-Sina'iya (literally "the industrial Yanbu") is the industrial city, established in 1975 by royal decree to create a Royal Commission to manage the effort to build a new modern city. It is the most southern part of Yanbu city. It is approximately 300 kilometers northwest of Jeddah (at $23.9845^{\circ} \mathrm{N}, 38.2533^{\circ} \mathrm{E}$ ) as shown in Figure 1.

Royal Commission (RCY) is managing Yanbu Industrial city. Its residents are mostly 130,000 total population with Existing Area is about $185 \mathrm{~km}^{2}$ and the expansion Area is about $420 \mathrm{~km}^{2}$. The industrial developed land is estimated to be 3240 Hectares (RCJY, 2012).

\section{Methodology}

Enterprise GIS is crucial in Planning and Development of Smart Cities. Enter- 
prise GIS consist of centralized information system platform can provides an IT framework for maintaining and deploying data and applications throughout every aspect of the city development life cycle. Every aspect of smart city whole process, starting from conceptualization, planning, and development to maintenance can be covered.

The steps to develop a smart city is different from smart city project to another but here we focus in the Royal commission yanbu industrial city smart city project and how the steps they follow in the project planning and implementation.

Step 1: Building a sustaining enterprise GIS.

Step 2: Developing an open access network fiber optic-network infrastructure.

Step 3: Implement add on smart services and important smart systems.

Step 4: integrate all the systems together using EGIS as platform.

Yanbu Industrial City uses methodology to implement Enterprise GIS for smart city as shown below Figure 2 .

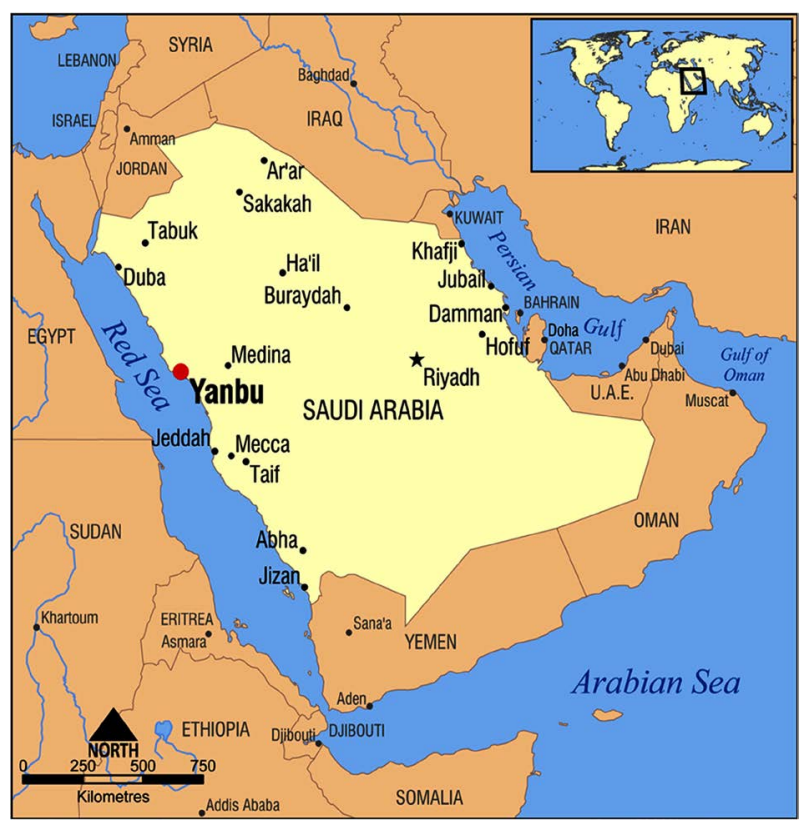

Figure 1. Map of Saudi Arabia showing the location of Yanbu Industrial City (Created by NormanEinstein, February 10, 2006).

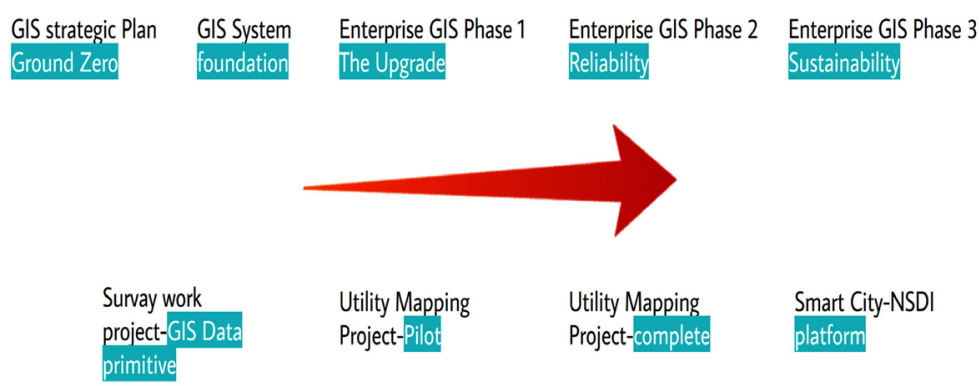

Figure 2. RCY Enterprise GIS to support smart city implementation. 
Location is a general factor and a key feature in every aspect of a smart city starting with detect the location for building, facility, road or human therefor maintenance or construction, warning or tracking, security or dispatch, Routing or sites providing common services or even the request for purchase and delivery to home. Every organization or individual need it for acting fast and response perfectly. Within every smart city service or system, the location becomes a key feature of the success and to interact with the citizens. The launch of common service or interactive system depends on the power of geolocation. hence a location platform (GIS based) platform must establish its backbone from the start to including ICT planning and deployment. A smart city needs a centralized information system based on GIS to provide a smart-IT framework which integrates every aspect of a smart city, starting from planning, development to maintenance.

Smart governance, smart infrastructure, smart energy, smart traffic management, smart security, public safety, smart Schools, Smart hospital, smart buildings, smart telecommunication, smart light system, smart crowd management, smart waste and smart service delivery are some of the pillars components of any smart city.

Enterprise GIS integrates all these pillars of smart city development and management. Moreover, below the Figure 3 elaborates the concept of Yanbu Industrial City Enterprise GIS for Smart City.

1) Fiber: Fiber-optic communication

2) OAN: open access network

3) Data Center: facility composed of networked computers and storage

4) EDMS: electronic document management system

5) ERP: Enterprise resource planning

6) HIS: Health System

7) UOC: unified operations center

8) BI: business intelligence

9) City Engine: Esri product to smart city planning

10) City console: city management Decision-makers

11) GeoEvent Processor: provides the capability to share Realtime information with users and other systems

In Figure 3, we see how the enterprise geographic information system become a platform for the smart city that can handle all the essential component of that smart city project. That include data streaming, internet of things (IOT), ICT, sensors and integration with other systems such as oracle ERP, Building management system BIM, primavera, scars and security surveillance and monitoring systems, artificial intelligence and more etc.

The EGIS system in the background run as a platform managing all of that but also in the front end can create a systems that support smart city operation as in our research we focus on some of these systems that implemented in royal commission of Yanbu and produced by enterprise GIS. 


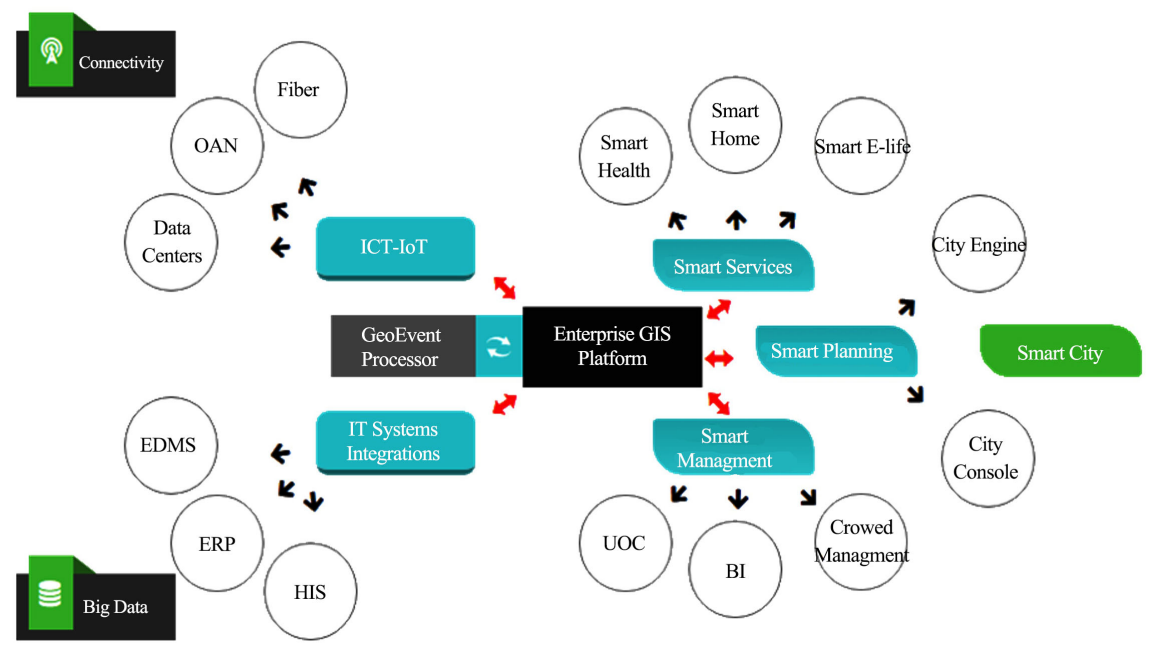

Figure 3. Yanbu Industrial City E-GIS platform concept in the smart city architecture.

GeoEvent Processor is sure to be a game changer in many industries, including fleet and asset management, telematics, defense and intelligence operations, public works, public health, forestry, mining, water and petroleum management, public safety and emergency management, transportation, and utilities [4].

\section{Results}

Absolute integrated system that become the core platform for smart city and help to deploy a massive value-added service in no time.

An enterprise GIS manage wide access to geospatial data and Systems and applications throughout the smart City. The usefulness as main platform:

- Extending geospatial capabilities to an enterprise community.

- Using a common infrastructure for building and deploying smart solutions

- Increase features of other enterprise systems by adding the value of geographic information

- Increasing overall operating efficiency and extracted analytical information.

Geospatial information platform for smart city can also be integrated with other enterprise applications to geo-enable executive analysis and decision-support systems such as SAP HANA, Oracle (ERP), Building management system (BIM), Health management system (HIS), Land management systems (LMS), etc.

Here is example how the smart value-added services work using the GIS platform.

1) Smart Pole Figure 4: streetlight pole not just as smart as detect any fault and theft of streetlights. With sensors, lights can go dim when they aren't needed, and authorities can get a text message almost instantly whenever there is a fault or tampering in streetlights. It now smarter more and more and even become as essential component of every smart city. because it can carry a lot of sensors and devices and even connectivity with weather sensor, wind sensor, humidity sensor and temperature sensor will serve as station for many city agen- 
cies such as fire stations and environmental control and called a smart pole in most of smart city projects, as shown in Figure 4 with camera add on, police, road control, traffic police and the digital signage will add investment and awareness.

Wi-Fi hot spot will make this pole like a router and will give the people around it free internet and more as shown in Figure 5.

\section{Conclusions}

This study set out to focus on the smart city projects using enterprise (GIS) and even with remarkable modern and innovative development and urban development; bigger urban areas are confronting wellbeing and manageability challenges. One of these challenges is the spatial data, for example, smart light system, smart surveillance security system, smart traffic system, smart crowd management system and all intelligent analytics systems need spatial data to mapping all this services and interact with it. "A key strategy enabling this involves the overhaul of data management procedures in late 2015 to marry resident addresses (which in Japan often fail to provide a precise geophysical location) to Geospatial Information Systems (GIS) co-ordinates and various demographic databases" [5].

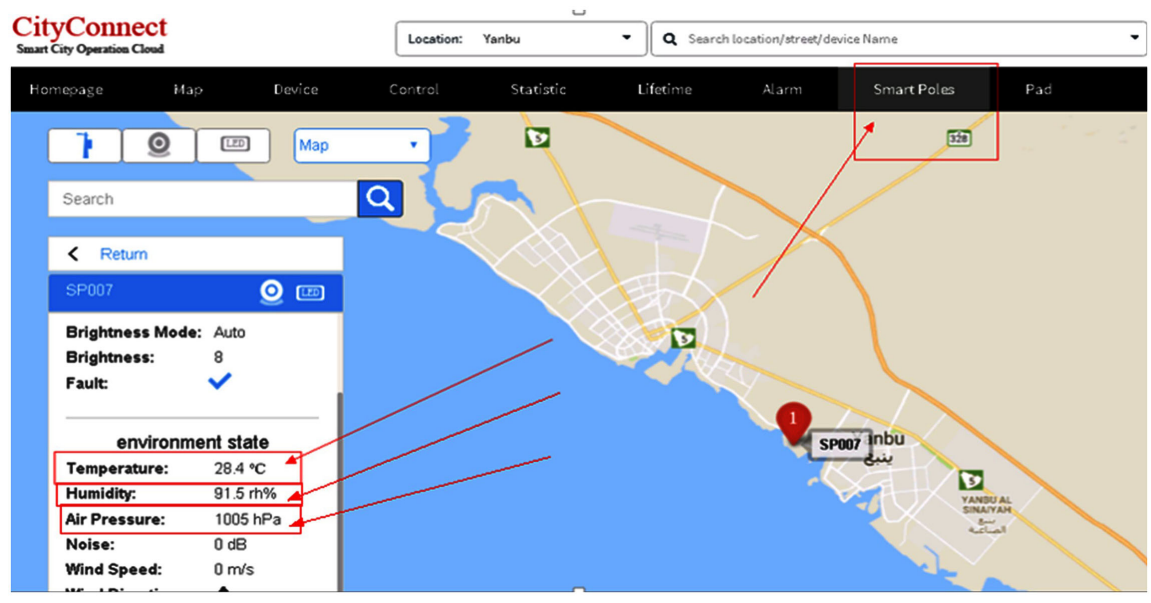

Figure 4. Smart pole system.

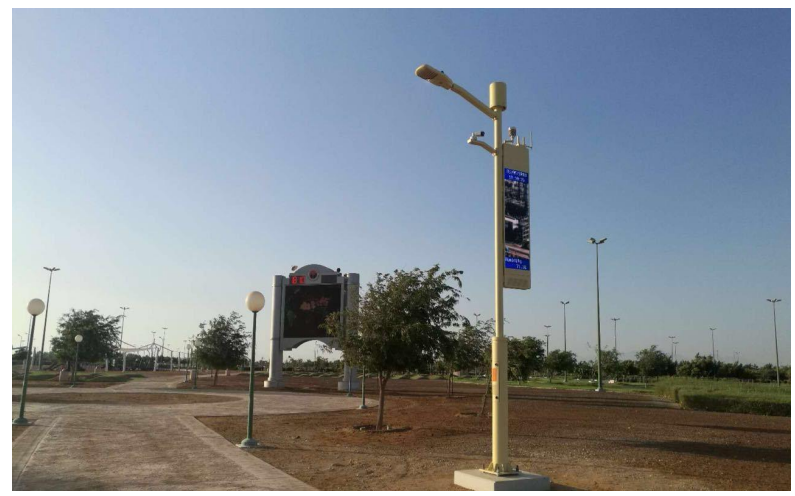

Figure 5. Smart pole with sensors. 
A Smart City could be an answer to overcomes these challenges using Enterprise GIS (The Smart City Initiatives is mostly a clever and playful way to address issues of unplanned urbanization.

On higher level, Geospatial data and geographic information systems (GISs) are essential components for building smart cities in a basic way that maps the physical world into virtual environment as a referencing framework. On higher level, GIS has been becoming very important in smart cities on different sectors. In the digital city era, digital maps and geospatial databases have long been integrated in workflows in land management, urban planning and transportation in government. People have anticipated GIS to be more powerful not only as an archival and data management tool but also as spatial models for supporting decision-making in intelligent cities.

Yanbu industrial city as a case study of GIS pervasive applications, which has strategically made a master plan of national information infrastructure and has been implementing geospatial collaboration environments for public and private sectors. Royal Commission of Yanbu uses Enterprise GIS to build Yanbu Industrial City as a Smart City, moreover, enhance urban operations and management; far-term planning, and exhaustive impact assessment studies of various policy options.

\section{Conflicts of Interest}

The authors declare no conflicts of interest regarding the publication of this paper.

\section{References}

[1] Franccois, D. (2015) Smart City, Importance of the Where. https://www.effigis.com/en/smart-city-importance-of-the-where/

[2] Beevor, M. (2018) 6 Challenges Smart Cities Face and How to Overcome Them. https://statetechmagazine.com/article/2018/12/6-challenges-smart-cities-face-and-h ow-overcome-them

[3] Wang, T. (2013) Interdisciplinary Urban GIS for Smart Cities: Advancements and Opportunities. Geo-Spatial Information Science, 16, 25-34. https://doi.org/10.1080/10095020.2013.774108

[4] ESRI (2013) ArcGIS Enables Real-Time GIS. https://www.esri.com/about/newsroom/arcnews/arcgis-enables-real-time-gis/

[5] Trencher, Towards the Smart City 2.0. 